\author{
Normand A. Tremblay MD, ${ }^{*}$ Jean-François Hardy MD, ${ }^{*}$ \\ Jean Perrault PhD, $\nmid$ Michel Carrier MD $\ddagger$
}

\section{A simple classification of the risk in cardiac surgery: the first decade}

Since 1980, the operative risk in all our cardiac surgical patients has been assessed before surgery. In light of reports of changes in cardiac surgical populations, we reexamined our practice and risk classification. The purpose of this study was to compare the surgery performed, the characteristics of the patients operated upon and the hospital mortality in our institution in two epochs ten years apart. In 1989-90, the 2029 consecutive cardiac surgical patients who had the same operations as the 500 patients of a 1980 study in our institution were prospectively stratified using our risk classification based on the number of risk factors (RFs) present: normal-risk patient $=$ no $R F$, increased risk $=1 R F$, high risk $\geq 2 R F$ s. These two cohorts of patients were compared. From 1980 to 1990, the proportion of high-risk patients tripled whereas the proportion of normalrisk patients diminished by one third and the proportion of increased risks remained unchanged. The incidence of the following RFs increased: poor left ventricular function, advanced age, emergency surgery, reoperation and other systemic disorders. In coronary artery surgery patients, the incidence of unstable angina/recent myocardial infarction and of obesity also increased. In noncoronary artery surgery patients, the incidence of heart failure increased while obesity remained unchanged. The difference in hospital mortality among the three risk classes was significant within both study periods. The mortality in each risk class and total mortality did not change between 1980 and 1990. Complex surgery carried a higher mortality than simple surgery $18.7 \%$ vs $2.6 \%$ in 1980 and $11.7 \%$ vs $4.1 \%$ in 1990). A stable hospital mortality and an increase in the proportion of high-risk patients in the more recent pop-

\section{Key words}

ANAESTHESIA: cardiac;

COMPLICATIONS: mortality;

RISK: cardiac;

SURGERY: cardiac.

From the Departments of Anaesthesia, ${ }^{*}$ Surgery, $\ddagger$ and the Research Center, $\uparrow$ The Montreal Heart Institute and the Université de Montréal.

Address correspondence to: Dr. Normand A. Tremblay, Département d'Anesthésie-Réanimation, Institut de Cardiologie de Montréal, Montréal, Quebec, Canada, H1T 1 C8.

Accepted for publication 23rd August, 1992. ulation may be attributed to recently improved therapeutic measures. The risk classification that we use remains a practical, reliable and simple clinical tool to estimate outcome and quality of care. The required data are readily available at the preanaesthetic visit. Complex surgery is a new $R F$.

Depuis 1980, l'anesthésiste évalue le risque de décès lors de la visite préopératoire chez tous nos opérés du coeur. Suite à diverses communications faisant état de changements des caractéristiques chez des patients subissant une chirurgie cardiaque, nous avons réexaminé notre pratique et notre classification du risque opératoire. Le but de cette étude était de comparer les interventions chirurgicales, les caractéristiques des opérés, et la mortalité durant l'hospitalisation à deux époques séparées par une décennie. En 1989-90, 2029 patients consécutifs qui avaient subi les interventions décrites dans une étude portant sur 500 patients opérés en 1980, furent regroupés prospectivement selon notre classification basée sur la présence de facteurs de risques (FR): patient à risque habituel = aucun $F R$, risque accru $=1 F R$, risque élevé $\geq 2 F R$. Les deux populations furent comparées. De 1980 à 1990, la proportion de patients à risque élevé a triplé alors que celle des patients à risque habituel a diminué du tiers et la proportion de patients à risque accrru n'a pas changé. Lincidence de la dysfonction ventriculaire gauche, de l'âge supérieur à 65 ans, de la chirurgie urgente, de la réintervention, et d'autres atteintes systémiques sévères a augmenté. Chez les patients de chirurgie coronarienne, lincidence de d'angine instable/infarctus du myocarde récent et d'obésité a augmenté. Chez les opérés de chirurgie non coronarienne, lincidence dinsuffisance cardiaque a augmenté tandis que lincidence d'obésité n'a pas changé. A chaque période étudiée, la mortalité entre les classes de risque était significativement différente. La mortalité dans chaque classe ainsi que la mortalité totale n'ont pas changé entre 1980 et 1990. La mortalité était plus grande dans le chirurgie complexe comparativement à la chirurgie plus simple $(7,8 \%$ vs $2,6 \%$ en 1980 et $11,7 \%$ vs $4,1 \%$ en 1990). De 1980 à 1990, bien que l'état de santé des opérés du coeur se soit détérioré, la mortalité est demeurée stable. L'amélioration de la qualité des soins pourrait expliquer cet état de fait. Notre classification du risque demeure un outil clinique pratique et simple, ainsi quin indicateur fiable du devenir des opérés du coeur. Cette classification peut également servir à évaluer la qualité des soins. La chirurgie complexe est identifiée comme un nouveau FR. 
To assess the risk of hospital mortality related to cardiac surgery, Paiement et al. ${ }^{1}$ devised, in 1980, a simple method of classifying patients before surgery, based on the presence of risk factors (RFs) associated with adverse outcome. Since then, the risk of all our cardiac surgical patients has been evaluated at the time of the preanaesthetic visit using this method which was validated in $1983 .{ }^{2}$ In summary, 500 consecutive cardiac surgery patients operated upon in 1980 were prospectively classified. The study showed that the operated population at normal risk (no RF) had a mortality of $0.4 \%$, the patient group at increased risk (1 RF) had a mortality of $3 \%$, and the high-risk group ( $\geq 2 \mathrm{RFs}$ ) had a mortality of $12 \%$. Furthermore, 50 deaths following cardiac surgery were assessed retrospectively using the classification: $58 \%$ were high risks, $34 \%$ were increased risks and only $8 \%$ were normal risks.

In light of reports indicating deterioration of the health of patients presenting for heart surgery ${ }^{3-5}$ and in some cases of an accompanying poorer outcome, ${ }^{6,7}$ we undertook to reexamine our cardiac surgical population and our risk classification.

The purpose of this study was to investigate changes in cardiac surgical procedures, patients' characteristics, and the hospital mortality over a decade at the Montreal Heart Institute. To this end, a 1990 cohort of cardiac surgical patients was compared with the former 1980 patient population ${ }^{2}$ using the previously described risk classification. We also studied the relationship between risk classification and postoperative morbidity defined as the length of stay in the postoperative intensive care unit (ICU) and in the hospital after surgery. This was evaluated using the 1990 cohort only as the pertinent data for 1980 were not available.

\section{Methods}

The study was approved by the institutional Ethics Committee. The RFs of cardiac surgical mortality previously described ${ }^{1.2}$ are shown in Table I. They include the following definitions: poor left ventricular (LV) function LV ejection fraction $<0.3$ or left ventricular end diastolic pressure $>18 \mathrm{mmHg}$ at rest; unstable angina during the month prior to surgery - crescendo, nocturnal, or rest angina or persistent angina despite hospitalization for medical therapy; recent myocardial infarction (MI) - MI within six weeks of surgery; advanced age - $>65 \mathrm{yr}$; obesity - body mass index (weight $[\mathrm{kg}] \cdot$ height $[\mathrm{m}]^{-2}>30$ ); emergency surgery - surgery required urgently and carried out within $24 \mathrm{hr}$; other severe and uncontrolled systemic disturbance - the presence of one of the following: systolic pulmonary arterial pressure $>50 \mathrm{mmHg}$; uncontrolled systemic arterial hypertension; renal insufficiency; chronic lung disease; poor hepatic function; cerebrovas- cular insufficiency; severe arrhythmias; active endocarditis; cachexia. Patients were prospectively classified as normal, increased or high risk of early death during hospitalization following cardiac surgery according to the number of RFs present as shown in Table I.

In 1980, 500 consecutive patients were included in a prospective study to define and to establish the risk classification of operative mortality related to cardiac surgery. ${ }^{2}$ This group of patients is the 1980 population referred to in the present study. From November 1988 to November 1990, 2124 consecutive cardiac surgical patients were classified prospectively according to operative risk as described above. Ninety-five patients were excluded from the comparison because they had surgical procedures that were not reported in the 1980 study. These surgical procedures were either new (mainly cardiac transplantations and electrophysiologic guided surgery, 60 patients) or rarely performed (thoracic aortic aneurysms, repair of post-MI ventricular septal defects, complex valve surgery, cardiac tumours or trauma, etc., 35 patients). The remaining 2029 patients form the 1990 population that is compared with the 1980 population. All pertinent data were computerized (QUADRA700, Apple Computers, Inc. Cupertino CA) using an appropriately edited database (4th Dimension (tm) ACUIS, Inc., Cupertino CA).

This study compares the type of surgical procedures, the preoperative RFs, and the classes of patients as they relate to the postoperative surgical mortality during hospitalization both within and between the two patient populations of 1980 and 1990. Also, as in 1980, the data were studied to determine if gender, left main coronary artery stenosis (LMCAS) and complexity of surgery were associated with increased mortality.

The relationship of the number of RFs per patient to mortality, to length of stay in postoperative ICU and to length of postoperative hospitalization was examined in the 1990 population.

Analysis of the data was performed using ANOVA for continuous variables, Chi-square for $>2$ categorical variables and Z-proportion for two categorical variables. Statistical significance was established at $P<0.05$. Statistical analysis was done using a computer program (Statview (tm), Abacus Concepts Inc, Berkeley CA). Data are presented in terms of absolute number, percentage, odds ratio and $95 \%$ confidence interval $(95 \% \mathrm{CI})$.

\section{Results}

\section{Surgical procedures}

Comparing the frequency of surgical procedures between 1980 and 1990, Table II shows that repair of congenital defect decreased while coronary artery surgery (CAS), 
TABLE I Risk factors and risk classification for heart surgery

Risk factors
Poor left ventricular function
Unstable angina or recent myocardial infarction
Evidence of heart failure
Advanced age
Obesity
Emergency surgery
Reoperation
Other severe and uncontrolled systemic disturbances
Patient classification
Normal risk $=$ no risk factor
Increased risk $=1$ risk factor
High risk $\geq 2$ risk factors

TABLE II Surgical procedures performed in 1980 and 1990

\begin{tabular}{lrrrrrr}
\hline & \multicolumn{2}{c}{1980} & & \multicolumn{2}{l}{1990} \\
& \multicolumn{2}{c}{$(n=500)$} & & \multicolumn{2}{l}{$(n=2029)$} \\
\cline { 2 - 3 } \cline { 6 - 7 } & $n$ & $(\%)$ & & $n$ & $(\%)$ \\
\hline Congenital defect repair & 17 & $(3.4)$ & & 9 & $(0.4)^{*} \dagger$ \\
Coronary surgery & 350 & $(70.0)$ & & 1507 & $(74.2)$ \\
- Coronary bypass & 320 & $(64.0)$ & & 1490 & $(73.4)^{*} \dagger$ \\
- Left ventricular aneurysm & 30 & $(6.0)$ & & 17 & $(0.8)^{*} \dagger$ \\
Valve surgery & 113 & $(22.6)$ & & 414 & $(20.4)$ \\
- Open mitral commissurotomy & 11 & $(2.2)$ & & 16 & $(0.8)^{*} \ddagger$ \\
- Mitral valve replacement & 45 & $(9.0)$ & & 129 & $(6.4) \S$ \\
- Aortic valve replacement & 38 & $(7.6)$ & & 172 & $(8.5)$ \\
- Multiple valve surgery & 19 & $(3.8)$ & & 97 & $(4.8)$ \\
Combined valvular and coronary & & & & & \\
$\quad$ surgery & 20 & $(4.0)$ & & 99 & $(4.9)$ \\
\hline
\end{tabular}

*Significant difference between 1980 and 1990.

$\dagger P<0.0001$.

$\ddagger P<0.05$.

$\S P=0.051$.

valve surgery and combined valvular and CAS surgery did not change. Within CAS surgery, isolated CAS increased and $\mathrm{LV}$ aneurysmectomy decreased whereas within valve surgery, open mitral valve commissurotomy decreased.

\section{Incidence of risk factors}

To compare the incidence of RFs between the two study periods, the patients were divided into two relatively homogeneous groups: the CAS group and the noncoronary artery surgery (NCAS) group (Table III).

In both groups of patients, the incidence of poor LV function, advanced age, emergency surgery, reoperation, and presence of other severe and uncontrolled systemic disturbances increased from 1980 to 1990 . In CAS patients, the incidence of unstable angina/recent $\mathrm{MI}$ and of obesity increased from 1980 to 1990 . The incidence of heart failure remained unchanged. In NCAS patients, the incidence of heart failure increased while that of obesity and unstable angina/recent MI remained unchanged from 1980 to 1990.

\section{Risk evaluation}

In $1990,58 \%$ of all the patients were at high risk compared with $18 \%$ in 1980 whereas the incidence of normal risk decreased from $50 \%$ to $14 \%$. The incidence of increased-risk patients did not change (Table IV). The hospital mortality among the three risk classes was different in both study periods but the mortality within each risk class and for all patients did not change from 1980 to 1990 .

The 100 nonsurvivors in the 1990 population were distributed as follows: two had been classified normal risks (one was an aortic valve replacement who died from severe refractory arrhythmias just before discharge and the other sustained a perioperative MI probably related to an unsatisfactory and difficult intramyocardial left anterior descending bypass graft), eight had been classified increased risks and 90 had been classified high risks. The descending order of frequency of the RFs in these nonsurvivors was: other severe and uncontrolled systemic disturbances (59\%); unstable angina/recent MI (57\%); poor LV function (55\%); advanced age (50\%); reoperation $(36 \%)$; obesity $(18 \%)$; emergency surgery (17\%); and heart failure (12\%).

Table $\mathrm{V}$ shows that the odds ratio of the relative risk of mortality in the 1980 patients classified at increased risk compared to patients at normal risk did not reach statistical significance (odds ratio $8.1,95 \% \mathrm{CI}: 0.86-76$, $\chi^{2}=3.365$ and $P>0.05$ ). Patients classified at high risk had a thirty-five-fold greater risk of mortality than patients classified at normal risk (odds ratio $34.8,95 \%$ CI: $9-134, \chi^{2}=23.906$ and $P<0.05$ ).

Likewise, in 1990 the odds ratio of the relative risk of mortality in patients classified as increased risk compared to patients considered as normal risk was not significant (odds ratio $=2.1,95 \%$ CI: $0.20-21.8, \chi^{2}=3.3$ and $P>0.05$ ). Patients classified as high risk had a twelvefold greater risk of mortality than normal risk patients (odds ratio $=11.9,95 \% \mathrm{CI}: 3.8-37.4, \chi^{2}=17.970$ and $P<0.05$ ).

\section{Mortality in women having coronary surgery}

In both study periods, the mortality was not different between women and men having isolated CAS even though the incidence of high-risk patients was greater in women than in men (Table VI). The incidence of women who underwent isolated CAS did not change from $1980(60 / 320=18.8 \%)$ to $1990(305 / 1490=20.5 \%)$ $(P>0.05)$. 
TABLE III Incidence of risk factors in coronary and non-coronary artery surgery in 1980 and 1990

\begin{tabular}{|c|c|c|c|c|c|c|c|c|}
\hline & \multicolumn{4}{|c|}{ Coronary artery surgery } & \multicolumn{4}{|c|}{ Non-coronary artery surgery } \\
\hline & \multicolumn{2}{|c|}{$\begin{array}{l}1980 \\
(n=370)\end{array}$} & \multicolumn{2}{|c|}{$\begin{array}{l}1990 \\
(n=1606)\end{array}$} & \multicolumn{2}{|c|}{$\begin{array}{l}1980 \\
(n=130)\end{array}$} & \multicolumn{2}{|c|}{$\begin{array}{l}1990 \\
(n=423)\end{array}$} \\
\hline & $n$ & $(\%)$ & $n$ & $(\%)$ & $n$ & $(\%)$ & $n$ & $(\%)$ \\
\hline Poor left ventricular function & 34 & (9.1) & 338 & $(21.1)^{*+}$ & 7 & $(5.4)$ & 234 & $(55.3)^{*} \dagger$ \\
\hline Unstable angina or recent $\mathrm{MI}$ & 78 & $(21.0)$ & 967 & $(60.2)^{* \dagger}$ & 0 & $(0.0)$ & 12 & $(2.8)$ \\
\hline Heart failure & 5 & $(1.3)$ & 26 & $(1.6)$ & 7 & $(5.4)$ & 57 & $(13.4)^{* 8}$ \\
\hline Age $>65 y r$ & 37 & $(10.0)$ & 509 & $(31.7)^{* \dagger}$ & 15 & $(11.5)$ & 128 & $(30.2)^{*} \dagger$ \\
\hline Obesity & 36 & $(9.7)$ & 327 & $(20.4)^{* \dagger}$ & 15 & (11.5) & 39 & $(9.2)$ \\
\hline Emergency surgery & 10 & $(2.7)$ & 144 & $(9.0)^{* \dagger}$ & 2 & $(1.5)$ & 30 & $(7.1)^{*} \S$ \\
\hline Reoperation & 21 & $(5.7)$ & 180 & $(11.2)^{*} \S$ & 15 & $(11.5)$ & 189 & $(44.7)^{*} \dagger$ \\
\hline Other systemic disorders & 22 & $(5.9)$ & 444 & $(27.7)^{*} \dagger$ & 32 & $(24.4)$ & 239 & $(56.5)^{*} \ddagger$ \\
\hline
\end{tabular}

*Significant difference between 1980 and 1990.

$\dagger P<0.0001$.

$\ddagger P<0.001$.

$\S P<0.05$.

TABLE IV Distribution of patients and of non-survivors in 1980 and 1990

\begin{tabular}{|c|c|c|c|c|c|c|c|c|}
\hline \multirow[b]{3}{*}{ Risk class } & \multicolumn{4}{|c|}{ All patients } & \multicolumn{4}{|c|}{ Non-survivors (mortality) } \\
\hline & \multicolumn{2}{|c|}{$1980+ \pm$} & \multicolumn{2}{|c|}{$1990 \dagger t$} & \multicolumn{2}{|l|}{$1980 \dagger \ddagger$} & \multicolumn{2}{|l|}{$1990+\div$} \\
\hline & $n$ & (\%) & $n$ & (\%) & $n$ & (\%) & $n$ & (\%) \\
\hline Normal & 251 & $(50.2)$ & 291 & $(14.3)^{*} \ddagger$ & $1 / 251$ & $(0.4)$ & $2 / 291$ & $(0.7)$ \\
\hline Increased & 159 & $(31.8)$ & 556 & (27.4) & $5 / 159$ & $(3.1)$ & $8 / 556$ & $(1.4)$ \\
\hline High & 90 & $(18.0)$ & 1182 & $(58.3)^{*} \ddagger$ & 11/ 90 & $(12.2)$ & $90 / 1182$ & (7.4) \\
\hline Total & 500 & & 2029 & & $17 / 500$ & (3.4) & $100 / 2029$ & (4.9) \\
\hline
\end{tabular}

* Significant difference between 1990 and 1980.

†Significant difference among risk classes within each study period.

$\ddagger P<0.0001$.

TABLE V Relative risk of operative death compared with normal risk patients

\begin{tabular}{lcc}
\hline & 1980 & 1990 \\
\hline Increased risk & 8.1 & 2.1 \\
High risk & $34.8^{*}$ & $11.9^{*}$ \\
\hline
\end{tabular}

$* P<0.05$.

\section{Mortality and left main coronary artery stenosis}

In isolated CAS, mortality was not different between patients with or without LMCAS in both study populations even though the incidence of high-risk patients with LMCAS was greater than the incidence of high-risk patients without LMCAS (Table VII). The incidence of LMCAS did not change from $1980(44 / 320=13.8 \%)$ to $1990(183 / 1490=12.3 \%)(P>0.05)$.
Surgical mortality and complexity of the surgical procedure

In both study periods, mortality was higher in patients undergoing more complex surgery (multiple valve replacement, CAS combined with valve or ventricular aneurysmectomy) compared with patients having simpler procedures (Table VIII). In both study periods, more patients having complex surgery were at high risk than patients having simple surgery. Assuming the new or infrequently performed surgery in the 95 patients of the 1990 population was complex surgery, the incidence of complex surgery did not change from $1980(69 / 500=$ $13.8 \%)$ to $1990(213+95 / 2124=308 / 2124=14.5 \%)$ $(P=0.741)$.

\section{Risk factors and outcome}

Table IX shows that in the 2124 consecutive cardiac sur- 
TABLE VI Mortality and incidence of high-risk patients in women and men having isolated coronary artery surgery in 1980 and 1990

\begin{tabular}{|c|c|c|c|c|c|c|c|c|}
\hline & \multicolumn{4}{|l|}{1980} & \multicolumn{4}{|l|}{1990} \\
\hline & \multicolumn{2}{|l|}{ Women } & \multicolumn{2}{|l|}{ Men } & \multicolumn{2}{|l|}{ Women } & \multicolumn{2}{|l|}{ Men } \\
\hline & $n /$ total & $\%)$ & $n /$ total & (\%) & $n /$ total & (\%) & $n /$ total & (\%) \\
\hline Non-survivors & $3 / 60$ & $(5.0)$ & $4 / 260$ & (1.5) & $13 / 305$ & (4.3) & $36 / 1185$ & $(3.0)$ \\
\hline High-risk & $15 / 60$ & $(25.0)$ & $28 / 260$ & $(10.8) \dagger \S$ & $188 / 305$ & $(61.6)^{*} \ddagger$ & $619 / 1185$ & $(52.2)^{*}+\ddagger \S$ \\
\hline
\end{tabular}

*Significant difference between 1980 and 1990.

$\dagger$ Significant difference between women and men within each study period.

$\ddagger P<0.0001$.

$\S P<0.01$.

TABLE VII Mortality and incidence of high risk in patients with and without left main coronary artery stenosis (LMCAS) having isolated coronary artery surgery in 1980 and 1990

\begin{tabular}{|c|c|c|c|c|c|c|c|c|}
\hline & \multicolumn{4}{|l|}{1980} & \multicolumn{4}{|l|}{1990} \\
\hline & \multicolumn{2}{|c|}{ With $L M C A S$} & \multicolumn{2}{|c|}{ Without LMCAS } & \multicolumn{2}{|c|}{ With LMCAS } & \multicolumn{2}{|c|}{ Without LMCAS } \\
\hline & $n /$ total & (\%) & $n /$ total & (\%) & $n /$ lotal & (\%) & $n /$ total & (\%) \\
\hline Non-survivors & $2 / 44$ & (4.5) & $5 / 276$ & (1.8) & $9 / 183$ & (4.9) & $40 / 1307$ & (3.1) \\
\hline High-risk & $11 / 44$ & $(25.0)$ & $32 / 276$ & $(11.6) \dagger \S$ & $116 / 183$ & $(63.4)^{*} \ddagger$ & $691 / 1307$ & $(52.9)^{*} \dagger \ddagger \S$ \\
\hline
\end{tabular}

*Significant difference between 1980 and 1990.

$\dagger$ Significant difference between patients with and without LMCAS within each study period.

$\ddagger P<0.0001$.

$\S P<0.05$.

TABLE VIII Mortality and incidence of high risk in patients having complex or single procedure in 1980 and 1990

\begin{tabular}{|c|c|c|c|c|c|c|c|}
\hline & \multicolumn{4}{|l|}{1980} & \multicolumn{3}{|l|}{1990} \\
\hline & \multicolumn{2}{|c|}{ Complex } & \multicolumn{2}{|l|}{ Single } & \multicolumn{2}{|l|}{ Complex } & Single \\
\hline & n/total & (\%) & $n /$ total & (\%) & $n /$ total & (\%) & $n /$ total \\
\hline Non-survivors & $6 / 69$ & $(8.7)$ & $11 / 431$ & $(2.6) \dagger \S$ & $25 / 213$ & $(11.7)$ & $75 / 1816 \quad(4.1) \dagger \ddagger$ \\
\hline High-risk & $28 / 69$ & $(40.6)$ & $62 / 431$ & $(14.4) \dagger \ddagger$ & $171 / 213$ & $(80.3)^{*} \ddagger$ & $1011 / 1816(55.7)^{*} \dagger \ddagger \S$ \\
\hline
\end{tabular}

*Significant difference between 1980 and 1990.

$\dagger$ Significant difference between complex and single procedure within each study period.

$\ddagger P<0.0001$.

$\S P<0.05$.

gical patients of the 1990 population, the length of postoperative ICU stay, of total postoperative hospitalization, and the mortality increased with the number of RFs per patient. These data were not available for 1980 .

\section{Discussion}

Several classifications of patients according to the risk of adverse outcome in heart surgery have been pro- posed. ${ }^{8-19}$ They range from the very simple operator-andinstitution-specific ${ }^{10}$ to the very sophisticated and complex..$^{14,15,19}$ Some classifications ${ }^{13,16-18}$ such as the early one developed in our institution ${ }^{2}$ are effective and simple to use in the clinical setting.

The 1980 study consisted of "a prospective evaluation of the classification made in 500 consecutive patients undergoing heart surgery," 2 over a period of eight months. 
TABLE IX Length of stay in ICU, duration of total hospitalization and mortality according to the number of risk factors per patient in 1990

\begin{tabular}{|c|c|c|c|c|c|c|}
\hline \multirow{2}{*}{$\begin{array}{l}\text { Number of } \\
\text { risk factors }\end{array}$} & \multicolumn{2}{|c|}{ Patients } & \multirow{2}{*}{$\begin{array}{l}\text { Days in } \\
I C U\end{array}$} & \multirow{2}{*}{$\begin{array}{l}\text { Days in } \\
\text { hospital }\end{array}$} & \multicolumn{2}{|c|}{ Non-survivors } \\
\hline & $n$ & (\%) & & & $n$ & (\%) \\
\hline 0 & 295 & (13.9) & 4.3 & 8.6 & 2 & $(0.7)$ \\
\hline 1 & 569 & $(26.8)$ & 4.7 & 9.3 & 8 & (1.4) \\
\hline 2 & 570 & $(26.8)$ & 5.8 & 10.7 & 23 & $(4.0)$ \\
\hline 3 & 423 & $(19.9)$ & 5.8 & 11.5 & 42 & (9.9) \\
\hline$\geq 4$ & 267 & $(12.6)$ & 6.5 & 15.7 & 39 & $\underline{(14.6)}$ \\
\hline Total & $\overline{2124}$ & $\overline{(100.0)}$ & & & $\overline{114}$ & $(5.4)$ \\
\hline$P$ value & & 0.0001 & 0.0001 & 0.0001 & & 0.0001 \\
\hline
\end{tabular}

The 1990 population consists of 2029 consecutive patients having cardiac surgery over a period of $24 \mathrm{mo}$ in 1989 and 1990 and who had the same surgical procedures as the 1980 patients. In 1990 , there were 95 patients who had surgery that was not reported in 1980; these patients were excluded from the comparison. Some rarely performed procedures were absent from the 1980 population due to the relatively small size and short duration of that study. Although the compared populations are different in size, each of them was homogeneous since throughout the respective study periods there was no change in surgeons, anaesthetists, and technology used. The study is similar in design to the six major reports ${ }^{3-7,20}$ that compared cardiac surgical populations over time.

\section{Surgical procedures}

Among the changes in surgical practice in our institution from 1980 to 1990 the most noteworthy is the introduction of new surgery (cardiac transplantation and electrophysiological procedures) and the large decrease in ventricular aneurysmectomies. The decrease in the number of patients presenting for surgery of ventricular aneurysms may have resulted from the introduction of aggressive tissue salvaging therapy in acute myocardial ischaemia (calcium blocking agents, thrombolysis, combined nitroglycerin-heparin therapy, percutaneous coronary angioplasty, intra-aortic balloon counterpulsation) during the intervening decade.

\section{Patient characteristics}

The increased incidence of poor LV function in CAS patients is in agreement with most reports ${ }^{4-7}$ that have studied the evolution of CAS patients. Loop et al. ${ }^{20}$ studied the evolution of reoperations for CAS from 1969 to 1982 at the Cleveland Clinic. They reported that the incidence of poor LV function increased in these patients. In the present study the incidence of reoperation for CAS doubled from 1980 to 1990 . Therefore, it is not surprising that the incidence of poor LV function should have increased in patients who presented for CAS in 1990. They formed a subgroup of patients who could not be helped medically despite use of new therapeutic modalities developed over the intervening decade.

The threefold increase in the number of patients aged over $65 \mathrm{yr}$ from 1980 to 1990 is consistent with reports from other centres. The experience at Emory University ${ }^{7}$ over a comparative period of time showed that the proportion of elderly patients tripled. A study of CAS patients comparing 1975 with 1985 at the University of St. Louis Medical Centre ${ }^{6}$ reported a sevenfold increase of patients over 65 yr. The Cleveland Clinic reported ${ }^{5}$ a steadily increasing incidence of patients older than $69 \mathrm{yr}$ from 1970 to 1982.

From 1980 to 1990, the incidence of emergency cardiac surgery tripled. While some have reported a doubling in the incidence of urgent CAS, ${ }^{6,7}$ others conducted before $1982^{4,5}$ found no change in the incidence of emergency CAS. In this study, urgent cases came from failed coronary angioplasties (which was just beginning in 1980) and from cases of angina refractory to aggressive inhospital medical treatment. The increase in emergency NCAS was in large part due to acutely dysfunctional artificial biological valves.

From 1980 to 1990, the rate of reoperations doubled for CAS and quadrupled for NCAS. Similar increases are reported by other centres. ${ }^{6,7,20}$ In 1990 , approximately $20 \mathrm{yr}$ had elapsed since the introduction of CAS. During the first decade, CAS consisted almost exclusively of venous bypass grafting. In the long-term survivors, venous bypass grafts develop atherosclerosis, eventually occlude ${ }^{21}$ and reoperation is often required. In NCAS, most reoperations were for dysfunctional biological prosthetic valves which appeared promising when they became available in the early 1980's but which turned out to be less durable than mechanical valves. Similarly, the dysfunctional valve prostheses explain the increased incidence of heart failure in NCAS patients. 
The large increase in other systemic disorders (fourfold for CAS and twofold for NCAS) parallels the increased rate of reoperations and the increased number of older patients. It is known that patients presenting for reoperation ${ }^{* 20}$ and older patients ${ }^{6,20,22,23}$ are sicker. In addition, more of the NCAS patients required urgent surgical intervention which precluded optimization of their general condition. Similar increases in the incidence of other systemic disorders (hypertension, carotid artery disease, diabetes) have been observed by others. $3,4,7$

In 1990, the large increase in the incidence of unstable angina is attributed to the fact that the patients coming to CAS were those who could not have coronary artery or coronary-graft dilatation or in which such dilatation had failed. The patients whose angina yielded to aggressive medical in hospital were operated upon as promptly as possible but were not treated as emergencies.

\section{Risk factors as predictors of outcome in cardiac surgery} There are various classifications of cardiac surgical patients according to risk. ${ }^{12,13,16-18}$ Among these, the Veterans Administration Study ${ }^{14}$ and the New York State Study ${ }^{15}$ masterfully demonstrated the importance of using a uniform method of analysing RFs and hospital mortality rates if meaningful comparisons (including quality of care) between populations are to be made. Accordingly, the use of our classification permits the evaluation of the quality of care in this institution. Our classification has been shown to be more reliable than the ASA physical status classification and the Goldman Multifactorial Index in identifying patients at risk for postcardiac surgery complications. $\dagger$ Also when combined with perioperative events (perioperative MI and intraoperative surgical complications), this classification has been reported to be strongly predictive of mortality. $\ddagger$

*Fremes SE, Ivanov J, Weisel RD, Mickleborough LL. The increased risk of reoperative coronary revascularization. Clinical and Investigative Medicine, 1989; 12: C42. Abstract presented at the Canadian Cardiovascular Society Annual Meeting, 1989, Vancouver.

$\dagger$ Paiement B, Barron M, Machado R, El-Ert A, Townsend S, Hirsch $J$. Predicting mortality and morbidity in cardiac surgery. A comparison of three methods. Poster Abstract presented at the Society of Cardiovascular Anesthesiologists 1986 Meeting in Montreal.

$\ddagger$ Mantia AM, Brinkmeyer SD, Ingram M, Ammon J, Canose $J L, D^{\prime} A$ mico $F$. Which perioperative variables are predictives of survival in elective coronary bypass grafting surgery in nonuniversity hospitals? Abstract of oral presentation presented at the Society of Cardiovascular Anesthesiologists 14th Annual Meeting in 1992 in Boston, MA.
All studies comparing cohorts of cardiac surgical patients over time report a decrease in the number of optimal candidates. Some studies ${ }^{4,5,8}$ reported a decrease in operative mortality which they attributed to improved therapeutic modalities. Other studies ${ }^{3,6,7}$ reported increased operative mortality. These diverging results may be due to differences in the time periods compared or to differences in risk assessment and assignment.

The higher incidence of many RFs and the more than threefold increase in high-risk patients over the decade separating the two study groups were not followed by a significant increase in total mortality. This may result from new and improved therapeutic measures including: drugs ("inodilators," calcium blocking agents, antiarrhythmics, coagulants); equipment (membrane oxygenators, blood filters, ST-segment monitors, floating pulmonary arterial catheters with pacing and/or oximetric options); surgical techniques (internal mammary grafts); anaesthetic techniques (scrupulous maintenance of optimal haemodynamic state); cardiac protection. The results of this study indicate that the quality of care has improved since 1980.

Notwithstanding progress in anaesthesia and in surgery, the evaluation of the operative risk by the odds ratio in 1990 shows that patients with two or more RFs had a twelvefold greater risk of mortality than patients with no RF, a difference still present in today's practice. Patients presenting with one RF did not appear to be at statistically significant greater risk of hospital mortality than patients with no RF. This points to a weakness in the power of the classification and is related to the low prevalence of hospital mortality in cardiac surgery.

Our experience in 1980 and in 1990 shows that mortality in CAS did not vary according to sex. There are reports of similar results in patients aged $70 \mathrm{yr}$ or less. Women older than $70 \mathrm{yr}$, however, had a higher operative mortality than men over $70 \mathrm{yr}^{11,15} \mathrm{~A}$ higher cardiac surgical mortality in women ${ }^{9,24}$ and less than optimal treatment of women suffering from coronary artery disease is a serious ongoing concern referred to as the "Yentl syndrome" 25 wherein women tend not to obtain the same treatment as men (specifically CAS) until they manifest florid severe coronary artery disease or until they suffer an MI. In this study, the greater incidence of high risk in women compared with men for CAS in 1980 and 1990 may reflect this.

The 1980 study also examined the possibility that LMCAS might be associated with increased mortality in CAS patients. The data presented here show that in 1980 and in 1990 there was no difference in mortality in CAS patients with or without LMCAS. Earlier studies ${ }^{5,26}$ had shown that LMCAS was a predictor of increased mortality in CAS but data from the Cleveland 
Clinic showed that since the 1980's, LMCAS has been neutralized as a $\mathrm{RF}^{5}$

The 1980 study also examined the mortality in patients having complex cardiac surgical procedures compared with patients having more simple cardiac surgery. There was a threefold difference in mortality according to the complexity of cardiac surgical procedure in 1980 and in 1990, which is in accordance with a similar study by Hannan. ${ }^{15}$ However, a multivariate logistic regression analysis of the data would be required to establish complexity of surgery as a separate RF.

Since the evaluation of the risk classification as it relates to postoperative morbidity was not the prime object of this study, morbidity was evaluated simply by observing the length of stay in postoperative ICU and the length of postoperative hospitalisation in the 1990 patients. Morbidity was related to the number of RFs per patient, a finding which further extends the usefulness of the classification. This has also been noted at the Bristol Royal Infirmary ${ }^{16}$ and at the Cleveland Clinic. ${ }^{18}$

\section{Conclusion}

The results of this comparison of two cohorts of prospectively stratified cardiac surgical patients ten years apart in the same institution show that for the same surgical procedures, the patients operated upon were much less healthy in 1990 than in 1980 . Yet, the hospital mortality did not change - a fact that we attribute to the availability of new and improved therapeutic modalities permitting better quality of care in 1990 . The mortality among the three classes of patients remained different in 1990 as was the case in the 1980 population showing that the risk classification described and used in this study remains valid.

Sex and LMCAS were not RFs. Complexity of cardiac surgery appeared to be an independent RF in cardiac surgery. There was a positive relationship between the number of RFs of a patient and postoperative morbidity.

The Montreal Heart Institute risk assessment classification is a useful clinical tool to predict hospital mortality and morbidity after cardiac surgery and to evaluate the quality of care in our institution.

\section{Acknowledgements}

The authors gratefully acknowledge the contributions of all the members of the Department of Anaesthesia: Drs. Sylvain Bélisle, Robert Blain, Réjean Laberge, Philippe Sahab, Norman Searle, and Jean Taillefer for their participation in the study; Micheline Roy RT for the screening and collection of the data; Bernard Paiement MD, for advice; Jean-Guy Maillé MD, Marcel Boulanger MD, Gilles L'Espérance PhD, Monique Robert BA for help in revising the manuscript; the members of the Department of
Surgery of the Montreal Heart Institute for their cooperation; Christiane Lussier and Mary Morello for preparation of the manuscript.

\section{References}

1 Paiement B, Maillé JG, Boulanger $M$, et al. La visite préopératoire en chirurgie cardio-vasculaire. Can Anaesth Soc J 1980; 27: 584-92.

2 Paiement B, Pelletier C, Dyrda I, et al. A simple classification of the risk in cardiac surgery. Can Anaesth Soc $\mathrm{J}$ 1983; 30: 61-8.

3 Kouchoukos NT, Oberman A, Kirklin JW, et al. Coronary bypass surgery: analysis of factors affecting hospital mortality. Circulation 1980 (Suppl I); 62: 1-84-9.

4 Miller DC, Stinson EB, Oyer PE, et al. Discriminant analysis of the changing risks of coronary artery operations: 1971-1979. J Thorac Cardiovasc Surg 1983; 85: $197-213$

5 Cosgrove DM, Loop FD, Lytle BW, et al. Primary myocardial revascularization. Trends in surgical mortality. J Thorac Cardiovasc Surg 1984; 88: 673-84.

6 Naumheim KS, Fiore AC, Wadley JJ, et al. The changing profile of the patient undergoing coronary artery bypass surgery. J Am Coll Cardiol 1988; 11: 494-8.

7 Jones EL, Weintraub WS, Craver JM, Guyton RA, Cohen $C L$. Coronary bypass surgery: is the operation different today? J Thorac Cardiovasc Surg 1991; 101: 108-15.

8 Loop FD, Berrettoni JN, Pichard A, Siegel W, Razavi M, Effler $D B$. Selection of the candidate for myocardial revascularization. A profile of high risk based on multivariate analysis. J Thorac Cardiovasc Surg 1975; 69: 40-51.

9 Kennedy JW, Kaiser GC, Fisher $L D$, et al. Clinical and angiographic predictors of operative mortality from the collaborative study in coronary artery surgery (CASS). Circulation 1981; 63: 793-802.

10 Urzua J, Dominguez P, Quiroga $M$, et al. Preoperative estimation of risk in cardiac surgery. Anesth Analg 1981; 60: 625-8.

11 Junod FL, Harlan BJ, Payne J, et al. Preoperative risk assessment in cardiac surgery: comparison of predicted and observed results. Ann Thorac Surg 1987; 43: 59-64.

12 Edwards FH, Albus RA, Zajtchuk R, et al. Use of a Bayesian statistical model for risk assessment in coronary artery surgery. Ann Thorac Surg 1988; 45: 437-40.

13 Parsonnet V, Dean D, Bernstein AD. A method of uniform stratification of risk for evaluating the results of surgery in acquired adult heart disease. Circulation (Suppl I) 1989 ; 79: I-3-12.

14 Grover FL, Hammermeister KE, Burchfiel C. Initial report of the Veterans administration preoperative risk assessment study for cardiac surgery. Ann Thorac Surg 1990; 50: 12-26. 
15 Hannan EL, Kilburn H, O'Donnell JF, Lukacik G, Sheilds EP. Adult open heart surgery in New York state. An analysis of risk factors and hospital mortality rates. JAMA 1990; 264: 2768-74.

16 Bolsin SN, Morgan C, Ray R. A simple, preoperative scoring system for predicting mortality and intensive care unit stay in adult patients undergoing heart surgery with cardiopulmonary bypass (abstract). Cardiothoracic Vasc Anesth 1990; 4 (Suppl 3): 133.

17 McCarthy $R$, Tuman K, Corey E, Ivankovich AD. A simplified risk scoring system for patients undergoing cardiac surgery (abstract). Anesthesiology 1991; 75: Al14.

18 Higgins TL, Estafanous FG, Loop FD, Beck GJ, Blum $J M$, Paranandi $L$. Stratification of morbidity and mortality outcome by predictive risk factors in coronary artery bypass patients. A clinical severity score. JAMA 1992; 267: 2344-8.

19 O'Connor GT, Plume SK, Olmstead EM, et al. Multivariate prediction of in-hospital mortality associated with coronary artery bypass graft surgery. Circulation 1992; 85: 2110-8.

20 Loop FD, Lytle BW, Gill CC, Golding LAR, Cosgrove $D M$, Taylor $P C$. Trends in selection and results of coronary artery reoperations. Ann Thorac Surg 1983; 36: 380-8.

21 Campeau L, Enjalbert $M$, Lespérance J, et al. The relation of risk factors to the development of atherosclerosis in saphenous vein bypass grafts and the progression of disease in the native circulation. $N$ Engl J Med 1984; 311: 1329-32.

22 Salomon NW, Page US, Bigelow JC, et al. Coronary artery bypass grafting in elderly patients: comparative results in a consecutive series of 469 patients older than 75 years. J Thorac Cardiovasc Surg 1991; 101: 209-18.

23 Rich $M W$, Keller $A J$, Schechtman KB, Marshall $W G$, Kouchoukos NT. Morbidity and mortality of coronary bypass surgery in patients 75 years of age or older. Ann Thorac Surg 1988; 46: 638-44.

24 Khan SS, Nessim S, Gray R, Czer LS, Chaux A, Matloff $J$. Increased mortality of women in coronary bypass surgery: evidence for referral bias. Ann Intern Med 1990; 112: $561-7$.

25 Healy B. The Yentl syndrome (editorial). N Engl J Med 1991; 325: 274-6.

26 Chaitman BR, Rogers WJ, Davis $K$, et al. Operative risk factors in patients with left main coronary artery disease. $\mathrm{N}$ Engl J Med 1980; 303: 953-7. 